\title{
THE "SHARED ACCOUNTABILITY" APPROACH TO Physician PAYMent: Four OPTIONS FOR DeVeloping Accountable Care Organizations
}

\author{
Jackson Williams, J.D., M.P.A.*
}

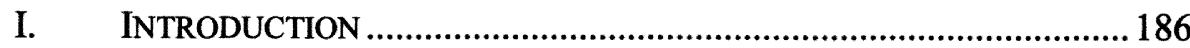

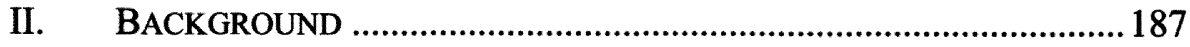

III. PERFORMANCE CRITERIA AND EVALUATION................................ 192

IV. MAKING THE SYSTEM WORK: TOOLS AT DOCTORS' DISPOSAL .... 197

V. FOUR MODELS OF SHARED ACCOUNTABILITY...............................2203

A. State Level.................................................................... 204

B. Local Level: Extended Hospital Medial Staff/Multi-Specialty

Group Practice ..................................................................... 206

C. Insurer-Convened ACO .................................................. 210

D. A "Competitive Dynamic" Approach to Updates.................... 211

VI. CONFLICTS LIKELY TO ARISE IN A SHARED ACCOUNTABILITY

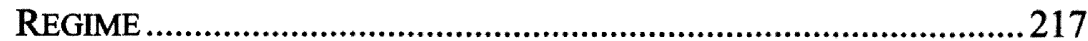

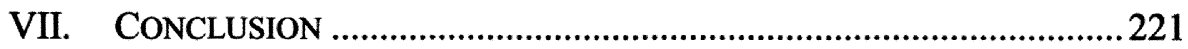

\section{ABSTRACT}

As policymakers confront the failure of fee-for-service medicine to properly align incentives for quality and efficiency, a "shared accountability" approach to physician payment has emerged. The newly conceived "Accountable Care Organization" would create "virtual" integrated delivery systems, while maintaining the fee-for-service (FFS) system. This would be accomplished by grouping doctors and hospitals together into discrete payment pools, through which collective performance could be measured and rewarded as a unit. This paper explores the concept of shared accountability in depth by attempting to flesh out possible mechanisms by which it could operate within the Medicare program and how provider incentives might be altered to encourage efficiency and quality. It presents four possible policy options for Medicare. It forecasts the conflicts and challenges likely to emerge in a shared accountability regime. The concluding comments assess how the Accountable Care Organization concept addresses some major criticisms of the Medicare program.

* J.D., Loyola University of Chicago School of Law; M.P.A., Governors State University; B.A., University of Illinois. The author has worked on health care issues for Public Citizen and AARP, and he served as one of the National Association Commissioners' Funded Consumer Representatives. 


\section{INTRODUCTION}

Few problems vex health care policymakers more than the failure of fee-for-service medicine to properly align incentives for quality and efficiency. At one time, many pinned their hopes on a system of "managed competition" in which health plans-ideally, integrated delivery systemswould be held accountable for care. 'Following the managed care backlash, policymakers began exploring rudimentary forms of "pay-forperformance," in which individual providers earn bonuses for achieving, or at least reporting, certain quality measures. ${ }^{2}$ Now, a third-wave approach has emerged, advanced by Dartmouth researchers, an Institute of Medicine committee, and several Medicare Payment Advisory Commission members. This "shared accountability" approach would create "virtual" integrated delivery systems, while maintaining the fee-for-service (FFS) system. This would be accomplished by grouping doctors and hospitals together into discrete payment pools, through which collective performance could be rewarded as a unit.

This paper explores the concept of shared accountability in depth by attempting to flesh out possible mechanisms by which it could operate within the Medicare program, and how provider incentives might be altered to encourage efficiency and quality. Part II of the paper reviews the literature in which the shared accountability concept was first articulated. Part III discusses possible performance goals that could be rewarded in such a system. Part IV discusses the techniques that doctors could use to achieve those goals when grouped into an accountable care organization.

Part V looks at four possible permutations of a shared accountability regime in Medicare. The first two envision a Congressional mandate assigning doctors to some type of accountable care organization ("ACO") at either the (1) state or (2) local level, enforced by target pool mechanisms similar to the Sustainable Growth Rate (SGR) system. ${ }^{3}$ The idea of local ACOs contemplates an initial assignment of physicians that assumes they are members of an "extended hospital medical staff," but would permit doctors to choose a different $\mathrm{ACO}$, either at a different hospital or a freestanding ACO resembling a multi-specialty group practice. A third model

1. Alain C. Enthoven, Market Forces and Efficient Health Care Systems, 23 HEALTH AffaIRs 25, 26 (2004) (citing Alain C. Enthoven, The History and Principles of Managed Competition, 1993 HeAlTH AfFaIRS Supp. 24-48).

2. Meredith B. Rosenthal \& R. Adams Dudley, Pay-for-Performance: Will the Latest Payment Trend Improve Care? 297 JAMA 740, 740 (2007).

3. 42 U.S.C. $\S 1395 \mathrm{w}-4$ (2009) (establishing the SGR, which sets a target for physician expenditures permitted to grow with national income and expansion of services to beneficiaries. In the event that expenditures exceed the target, the conversion factor used to calculate physician reimbursements under the fee schedule is reduced. If expenditures are below the target, the conversion factor is increased. This paper will make reference to this method of updating fees in the ensuing discussion of policy options). 
envisions voluntary ACOs being convened by insurers, a possibility suggested in the Institute of Medicine's pay for performance report. ${ }^{4}$ A final set of models envisions milder, incremental versions in which doctors might be encouraged to collectively pursue efficiency and quality measures without the imposition of any formal framework. This section includes discussion of two new Obama administration initiatives that may nudge physicians toward shared accountability arrangements.

Part VI discusses the conflicts and challenges likely to emerge in a shared accountability regime. The concluding comments assess how shared accountability proposals address some major criticisms of the Medicare program.

\section{BACKGROUND}

The rationale for pursuing a shared accountability approach is well stated by the Institute of Medicine in the introduction to its report on payfor-performance, Rewarding Provider Performance: Realigning Incentives in Medicare:

The current Medicare fee-for-service payment system is unlikely to promote quality improvement because it tends to reward excessive use of services; high-cost, complex procedures; and lower-quality care. Through bundled and prospective payment arrangements for institutions, Medicare has attempted to create incentives for efficiencies, but significant price and payment distortions persist.

Services that contribute greatly to high-quality care that are labor- or time-intensive and rely less on technical resources, such as patient education in selfmanagement of chronic conditions and care coordination, tend to be undervalued and are not adequately reflected in current payment arrangements. Little emphasis is placed on efficiency (achieving high clinical quality with a given amount of resources). The lack of incentives for comprehensive, coordinated care discourages services targeting early intervention and prevention that can ultimately reduce the use of expensive services, such as avoidable hospitalizations. Providers often miss opportunities for collaboration

4. Institute of Medicine, Rewarding Provider Performance: Aligning INCENTIVES IN MEDICARE (National Academies Press 2007). 
since the payment system rewards neither team management nor the integration of services across care settings. 5

Over the past two years, an increasing number of health policy experts have called for providers' "assum[ption of] 'shared accountability;", 6 "band[ing] together into organizations-whether traditional or virtual;" "develop[ment of] integrated care networks,", or other mechanisms imposing accountability for hand-offs, care transitions, referrals to other providers, and the long-term health status of patients, not simply for the care that an individual professional delivers during a particular episode of illness. All of these commentators contemplate joint accountability between physicians and hospitals, despite the fact that fee-for-service Medicare program separates these two parties into separate payment "silos." The foundation for the shared accountability approach emerged almost simultaneously from three sources:

- In its August 2006 report, the Institute of Medicine acknowledged that early pay-for-performance efforts would be provider-specific, but stressed that eventually, payment incentives should be structured to "stimulate collaboration and shared accountability among providers across care settings for better patient-centered health outcomes." It went on to call for "longitudinal, population-based measures that foster shared accountability of providers." ${ }^{" 10}$ Noting the difficulty of measuring an individual physician's performance, it proposed exploration of what it called "virtual groups"" as the unit to be measured.

- In a January 2007 Health Affairs article, Elliott Fisher and colleagues argued that

Medicare beneficiaries receive most of their care from relatively coherent local delivery systems comprising physicians and the hospitals where they work or admit their patients. Efforts to create accountable care organizations at this level-the extended hospital

5. Id. at 4 .

6. National Committee for Quality HealthCare, CEO Survival Guide: Pay FOR PERFORMANCE43 (2006 ed.), available at http://www.leapfroggroup.org/media/file/ HospitalCEOGuideto P4P.pdf (last visited May 15, 2010).

7. A High Performance Health System for the United States: An Ambitious Agenda for the Next President. THE COMMON FUND, Nov. 2007, at 19.

8. Hoangmai H. Pham \& Paul B. Ginsburg, Unhealthy Trends: the Future of Physician Services, 26 HEALTH AFFAIRS 1586,1596 (2007).

9. INSTITUTE OF MEDICINE, supra note 4, at 8.

10. Id. at 18 .

11. Id. at 118 . 
medical staff-deserve consideration as a potential means of improving the quality and lowering the cost of care. ${ }^{12}$

The article argued that creation of ACOs would allow better performance measurement, encourage reduction of excess capacity, and aggregate providers into units with the financial wherewithal to invest in health information technology or other quality initiatives.

- In a March 2007 report to Congress, the Medicare Payment Advisory Committee sketched out an "alternate path" to physician payment,

one that respects the diversity of the nation and its health care system, [that would] involve[] setting targets for geographic units and then permitting the fullest possible array of alternative - and voluntaryorganizational approaches within that geographic framework. In some geographic areas, ACOs may take the lead in organizing the effort to lower costs and improve quality... In some cases, state or local governments, medical societies, or others may play a role. $^{13}$

This report emphasized "shared savings"-warding physicians bonuses when good preventive care averts more expensive acute care downstream - as driving re-aligned incentives for efficiency.

One common thread linking these three sources is Fisher, who addressed the MedPAC meeting at which the term "accountable care organization" was coined and who served as a member of and spokesperson for the Institute of Medicine's Advisory Subcommittee on Pay for Performance. Fisher is associated with the Dartmouth Atlas project and that work very much informs the rationale for the shared accountability approach. Researchers at Dartmouth have documented wide geographic variations in the quality and efficiency of American health care. ${ }^{14}$ They have shown that

12. Elliott S. Fisher, et al., Creating Accountable Care Organizations: The Extended Hospital Medical Staff, 26 HEALTH AFFAIRS w44, w44 (2007) [hereinafter Fisher, et al., Creating Accountable Care Organizations].

13. Medicare Payment AdVisory Commission, Report to the Congress: ASSESSING ALternatives to the Sustainable Growth RATE SySTEM 188 (March 2007), available at http://www.medpac.gov/documents/Mar07_SGR_mandated_report.pdf (last visited May 15, 2010) [hereinafter MEDICARE PAYMENT ADVISORY COMMISSION, ASSESSING Alternatives].

14. See Elliott Fisher \& David Wennberg, Variations in the Longitudinal Efficiency of Academic Medical Centers 2004 HeAlTh AfFaIRS Suppl. Web Exclusives VAR19-32, 
fee-for-service medicine can and does produce high-quality, highly efficient health care in certain regions; but also that, in most regions, that level of care does not prevail. $^{15}$

Another common thread is the opinion shared by many health policy experts that integrated delivery systems - comprised of hospitals and multispecialty group physician practices-deliver better, more efficient care, ${ }^{16}$ and that the dynamics prevailing in such organizations might be replicated on a "virtual" basis.

The accountable care organization superficially resembles Independent Practice Associations and Physician Hospital Organizations, entities that sprang into being during the heyday of managed care. ${ }^{17}$ The ACO is seen as having the potential to harness some of the positive characteristics of managed care-such as a measure of financial risk assumed by physicians, the ability to coordinate care, and the infrastructure of an integrated delivery system-without the negative characteristics, such as a loss of physician autonomy, potentially harmful financial risk to physicians, or incentives to stint on care. ${ }^{18}$ This is because it remains a fee-for-service system, retaining independent proprietorships, and any financial incentives to stint on care can be counterbalanced, or outweighed, by incentives to improve patient outcomes.

Unlike the IPA and PHO, the ACO need not be a formal partnership or corporate entity; all that is necessary is that a pool be delineated in Medicare's administrative structure that allows savings based upon efficiency or higher-quality care to be shared by the accountable physicians, or that permits bonuses to be added to the pool.

The table below shows how the shared accountability paradigm is intended to occupy a middle ground between the unbridled autonomy of feefor-service medicine and the strictures of managed care:

$\mathrm{http}: / /$ content.healthaffairs.org/cgi/content/abstract/hlthaff.var.19v1.

15. Id. at VAR25.

16. See, e.g., Laura Tollen, Physician ORganization in Relation to Quality and EFFicIENCY OF CARE: A SYNTHESIS OF RECENT Literature, The Commonwealth Fund (2008), available at http://www.commonwealthfund.org/ /media/Files/Publications/Fund\% 20Report/2008/Apr/ Physician\%20Organization\%20in\%20Relation\%20to\%20Quality\%20 and $\% 20$ Efficiency $\% 20$ of $\% 20$ Care $\% 20 \% 20 \mathrm{~A} \% 20$ Synthesis\%20of\%20Recent\%20Literatu /Tollen_physician_org_quality_efficiency_1121\%20pdf.pdf (last visited May 15, 2010).

17. Stephen M. Shortell \& Lawrence P. Casalino, Health Care Reform Requires Accountable Care System, 300 JAMA 95 (2008). Arguably, the ACO concept also encompasses multi-specialty group physician practices contracting with Blue Cross/Blue Shield of Massachusetts pursuant to its "Alternative Quality Contract" program, which combines a "global payment structure" with "incentive payouts" for surpassing quality thresholds. See BlueCross BlueShield Association, Changing Incentives to Promote Better Care, http://www.bcbs.com/issues/ uninsured/blue-cross-blue-shield-of-mass.html?templateName $=$ template-28719196\&print $=t$ (last visited July 30, 2008).

18. Allan H. Goroll, et al., Fundamental Reform of Payment for Adult Primary Care: Comprehensive Payment for Comprehensive Care. 22 J. OF GEN. INTERNAL MED. 410, 41314 (2007). 


\section{Characteristics of Physician Payment Systems}

\begin{tabular}{|c|c|c|c|}
\hline Dimension & $\begin{array}{l}\text { Fee for } \\
\text { Service }\end{array}$ & $\begin{array}{c}\text { Shared } \\
\text { Accountability }\end{array}$ & Managed Care \\
\hline $\begin{array}{l}\text { Doctors' } \\
\text { Financial Risk } \\
\text { for Quality and } \\
\text { Efficiency of } \\
\text { Care }\end{array}$ & Minimal & $\begin{array}{l}\text { Possible } \\
\text { negative update } \\
\text { to } \\
\text { reimbursement } \\
\text { schedule }\end{array}$ & $\begin{array}{l}\text { Possible loss of } \\
\text { withheld } \\
\text { reimbursement }\end{array}$ \\
\hline $\begin{array}{l}\text { Doctor } \\
\text { Autonomy }\end{array}$ & $\begin{array}{l}\text { Minimal } \\
\text { constraint, } \\
\text { although } \\
\text { tiering and } \\
\text { profiling are } \\
\text { potential } \\
\text { checks }\end{array}$ & $\begin{array}{l}\text { Constraint by } \\
\text { peer pressure }\end{array}$ & $\begin{array}{l}\text { Constraint by } \\
\text { utilization review } \\
\text { (and by superiors in } \\
\text { staff model HMO) }\end{array}$ \\
\hline $\begin{array}{l}\text { Doctor's } \\
\text { Financial } \\
\text { Incentive }\end{array}$ & $\begin{array}{l}\text { Greater } \\
\text { utilization, } \\
\text { with potential } \\
\text { for over-use }\end{array}$ & $\begin{array}{l}\text { Efficient } \\
\text { utilization }\end{array}$ & $\begin{array}{l}\text { Lower utilization, } \\
\text { with potential for } \\
\text { stinting on care }\end{array}$ \\
\hline $\begin{array}{l}\text { Objective of } \\
\text { Organizing } \\
\text { Delivery } \\
\text { System }\end{array}$ & $\begin{array}{l}\text { To earn target } \\
\text { income }\end{array}$ & $\begin{array}{l}\text { To replicate the } \\
\text { quality and } \\
\text { efficiency } \\
\text { prevailing in } \\
\text { FFS medicine } \\
\text { high-performing } \\
\text { regions }\end{array}$ & $\begin{array}{l}\text { To manage care in } \\
\text { accordance with } \\
\text { organization's } \\
\text { principles }\end{array}$ \\
\hline $\begin{array}{l}\text { Locus of } \\
\text { Accountability }\end{array}$ & $\begin{array}{l}\text { Individual } \\
\text { provider }\end{array}$ & $\begin{array}{l}\text { Accountable } \\
\text { Care } \\
\text { Organization }\end{array}$ & Health plan \\
\hline
\end{tabular}

To succeed in providing appropriate care to beneficiaries, a shared accountability regime must be precisely calibrated to achieve efficiency, not stinginess; to produce quality outcomes, not gaming; to be cooperative without being exclusive; and above all, to be perceived as fair by both patients and providers. Sufficient financial rewards must be available to spur investments of doctors' time and money and to provoke collaboration with colleagues - and uncomfortable confrontations when necessary. The possibility of unintended consequences would be daunting if not for the unacceptably poor performance of the current fee-for-service system and the largely unsatisfactory experience with its polar opposite, capitation. ${ }^{19}$

19. See, e.g., Toby Gosden, et al., Capitation, Salary, FeE-For-Service AND MiXed SYSTEMS OF PAYMENT: EFFECTS ON THE BEHAVIOUR OF PRIMARY CARE PHYSICIANS, (The Cochrane Collaboration ed., John Wiley \& Sons, Ltd. 2006) (2006), available at http:// 
Beyond addressing the deficiencies of fee-for-service and capitated medical practice, the accountable care organization also holds promise for achieving larger goals, such as improving the health of populations, as opposed to just individual patients ${ }^{20}$ and promoting better management of medical resources in a health care system thought to be inefficient and wasteful. $^{21}$

\section{PeRformance CRITERIA AND EVAluation}

The idea of an Accountable Care Organization begs two threshold questions: accountable for what and accountable to whom? The three payfor-performance goals identified by the Institute of Medicine-efficiency, clinical quality, and patient-centeredness - provide a good starting point for discussion of what a unit would be accountable for (discussion of to whom the unit is accountable is saved for later). A shared accountability regime envisions a population of Medicare beneficiaries as the unit of analysis for assessing performance on the three dimensions. Using a population as the unit of analysis provides a much richer basis for measuring performance than the individual provider or patient. Population-level quality measures may include outcome measures, where outcomes, not process compliance, constitute the value sought by the Medicare program and its beneficiaries.

Outcome measures at the level of the individual physician are for the most part impracticable, due to the small number of cases involved. At the population level, however, outcome measures can be scientifically valid and fair when the unit being measured has the ability to act collectively to improve performance. As Fisher and colleagues note, "implementation of performance measurement at this level could begin nationwide in relatively short order, especially when compared with the challenges of measurement within physicians' offices."22 This is because a wealth of population- and institution-level candidate measures already exists. Inferences about quality of care can be made by three sets of outcome measures using administrative claims data:

\section{Inpatient Quality Indicators (IQIs) $)^{23}$}

www.hpm.org/Downloads/Bellagio/Articles/Capitation_salary_fee-for-service_CochReview.pdf (last visited May 15, 2010).

20. David M. Lawrence, A Comparison of Organized and Traditional Health Care: Implications for Health Promotion and Prospective mMedicine. 44 METHODS INF. MED. 273, 275 (2005).

21. Christine K. Cassel \& Troyen E. Brennan, Managing Medical Resources: Return to the Commons? 297 JAMA 2518, 2518 (2007).

22. Fisher et al., supra note 12, at w55.

23. The Inpatient Quality Indicators (IQIs) are a set of measures that provide a perspective on hospital quality of care using hospital administrative da- 


\section{Patient Safety Indicators (PSIs) ${ }^{24}$}

\section{Medicare Ambulatory Care Indicators for the Elderly (MACIEs) ${ }^{25}$}

Most performance measures currently in use are process measures. For example, the HospitalCompare program abstracts samples of hospital medical records to infer hospital quality. ${ }^{26}$ An example seen in the table below is "PCI [percutaneous coronary intervention] Received Within 120 Minutes Of Hospital Arrival," the time to remove a blood clot. This is useful information but patients are more interested in their chance of survival. Such an outcome measure is seen immediately below on the table as "30Day Mortality for Acute Myocardial Infarction," which is an Inpatient Quality Indicator.

Another source of measurements is patient survey data. Self-reported health may be a good indicator of health care quality. Consumer Assessment of Health Plans (CAHPS) surveys ${ }^{27}$ measure this indicator but primarily provide trenchant data on the patient-centeredness dimension of care.

A third dimension of care, efficiency, remains devoid of any generally accepted measures. This may not be a problem to the extent that shared savings is the basis of performance awards. This is because many quality measures are based upon "avoidable hospitalizations," and it is the avoided

\footnotetext{
ta. These indicators reflect quality of care inside hospitals and include inpatient mortality for certain procedures and medical conditions; utilization of procedures for which there are questions of overuse, underuse, and misuse; and volume of procedures for which there is some evidence that a higher volume of procedures is associated with lower mortality.
}

Agency for Healthcare Research and Quality, Inpatient Quality Indicators Overview, http://www.qualityindicators.ahrq.gov/iqi_overview.htm

(last visited July 30,2008 ).

24. "The Patient Safety Indicators (PSIs) are a tool to help health system leaders identify potential adverse events occurring during hospitalization." Agency for Healthcare Research and Quality, Patient Safety Indicators Overview, http://www.qualityindicators.ahrq.gov /psi_overview.htm (last visited July 30, 2008).

25. Edward Westrick \& Stephen Kogut, Medicare Payment AdVisory COMmisSion, MEdicare AMBUlatory CARE INDICATORS For THE Elderly: REFINEMENT Of THE ACCESS TO CARE For THE ELDERLY PROJECT INDICATORS 2 (2006).

26. See Hospital Quality Alliance, Improving Care through Information Overview: Data Collection, Transmission \& Reporting, Apr. 16, 2008, ,http://www.qualitynet.org/dcs/ ContentServer?cid=1121785350618\&pagename=QnetPublic\%2FPage\%2FQnetTier2\& $\mathrm{c}=$ Page (last visited July 30,2008 ).

27. The Consumer Assessment of Healthcare Providers and Systems (CAHPS) program is a multi-year initiative of the Agency for Healthcare Research and Quality (AHRQ) to support the assessment of consumers' experiences with health care. The goals of the CAHPS program are twofold: Develop standardized patient questionnaires that can be used to compare results across sponsors and over time; and generate tools and resources that sponsors can use to produce understandable and usable comparative information for both consumers and health care providers.

Agency for Healthcare Research and Quality, The CAHPS Program, http:// www.cahps.ahrq.gov/content/cahpsOverview/OVER_Program.asp?p=101\&s=12 (last visited July 30, 2008) 
hospitalizations themselves that generate the physician bonuses in a shared savings regime. An example is one of the MACIEs, "Serious Short Term Complications of Diabetes Mellitus." The more pressing imperative is to ensure that avoided hospitalizations result from the provision of appropriate ambulatory care and not from stinting or gaming.

The following discussion references measures that could be examined if states were to be the level of accountability. It should be emphasized that these are cited for illustration only, as no group of measurements stands out as obvious criteria for rewards. It is also important to note that these measures have not in the past been applied to physicians-IQIs and PSIs use hospitals as the unit of analysis; MACIEs and CAHPS are population-level measures. The ACO, by charging both hospitals and their affiliated physicians with responsibility for the health of the population they serve, applied fused accountability on all entities involved. 


\section{Examples of Metrics Applicable to Populations of Medicare Beneficiaries}

Efficiency

State/Local National

Cost per medicare patient:

$\$ 9,400$

$\$ 7961$

Number of doctor visits during last

6 months of life

41.5

29

\section{Quality}

PCI Received Within 120 Minutes Of

Hospital Arrival

$128 \mathrm{~min}$

$107 \mathrm{~min}$

30-Day Mortality for Acute Myocardial

Infarction

$8.18 \%$

$6.05 \%$

Death Among Surgical Inpatients with Treatable

Serious Complications (Failure to Rescue) 138

Hospitalization For Respiratory Diagnosis in COPD/

Asthma

71

44

Serious Short Term Complications of Diabetes

Mellitus

65

55

Seniors reporting good, very good or excellent

health

$70.9 \%$

$69.3 \%$

\section{Patient-Centeredness}

CAHPS overall rating of health care patients received

Patients who always got appointment as soon as they Wanted

Note: Values are hypothetical

It is important to note that ACO goals must be set so that performance is rewarded based upon all three dimensions. Because cost can trade off against quality and access, crude measures of efficiency (e.g., cost alone) could encourage stinting in the other areas. Precisely how doctors would be rewarded for improvements is beyond the scope of this paper, but it would suffice to say that rewards should be structured so that doctors could share in any savings resulting from improved efficiency, so long as metrics for quality and patient-centeredness are no worse. Further, doctors should, if possible given resource restraints, receive additional money if efficiency is no worse than the target but quality and patient-centeredness scores are improved.

Suppose that: (a) the devolved SGR target pool provides a model for 
baseline efficiency; (b) Medicare's Physician Group Practice (PGP) demonstration ${ }^{28}$ provides a model for awarding an accountable organization shared savings; and (c) the Integrated Healthcare Association (IHA) provides a model for awarding bonuses based upon quality and patient experience measures. To take the example of an ACO comprising all of New Jersey physicians, a baseline pool of $\$ 10.8$ billion would be established. Imagine that after the first year of implementation, New Jersey physicians have lowered costs by five percent, or $\$ 540$ million, while maintaining the previous year's performance on process measures such as time to reperfusion, outcome measures such as hospital mortality, and CAHPS scores relating to access and experience. As in the PGP demonstration, doctors would be awarded eighty percent of the shared savings. Alternatively, suppose that Medicare expenditures remained constant, but quality and patient experience measures improved. Doctors could be awarded per-patient, permonth bonuses according to a formula as in the IHA program.

Over time, expectations for quality and patient-centeredness might be raised: if some units dramatically improved on those measures, states with similar demographics and resources might be expected to improve as well. Similarly, expectations for efficiency might be raised. Many commentators speak of about thirty percent of health care costs being wasted; ${ }^{29}$ achieving a goal of cutting this thirty percent would require that all ACOs operate with the efficiency of top-performing regions.

The three dimensions cited by the IoM are not exhaustive. Performance goals could integrate public health. Kindig argues that physician pay should include a " "pay-for-population health performance system' that would go beyond medical care to include financial incentives for the equally essential nonmedical care determinants of population health."30 Kindig does not propose a unit of accountability for such a program, yet a statelevel ACO would seem to fit naturally with this concept. An example of a public health indicator might be a decrease in standardized mortality rates. Rosenthal and Dudley suggest that a pay-for-performance scheme could include rewards for reducing disparities among underserved populations. ${ }^{31}$

Evaluating performance within a system of local ACOs would not be as straightforward as doing so on the state level. The sparse level of sam-

28. 42 U.S.C. $\$ 1395 \mathrm{cc}-1$ (2009).

29. See, e.g., Midwest Business Group on Health, Reducing the Cost of Poor Quality Health Care Through Responsible PuRChasing Leadership i (2003); John E. Wennberg, Elliott S. Fisher \& Jonathan S. Skinner, Geography and the Debate Over Medicare Reform, 2002 HEALTH AFFaIRS Web Exclusive w96, w97-w98.

30. David A. Kindig, A Pay-forPpopulation Health Performance System. 296 JAMA 2611, 2611 (2006). See also Michael McGinnis, Institute of Medicine, Special Remarks at the American Enterprise Institute for Public Policy Research Conference: Determinants of Avoidable Mortality, Investment in Health Promotion and Disease Prevention (July 23, 2008).

31. Rosenthal \& Dudley, supra note 2, at 743. 
pling required for statewide measurement would not be sufficient for smaller populations, requiring wider use of instruments such as CAHPS surveys or the Medicare Health Outcomes Survey.

\section{MAKING THE SYSTEM WORK: TOOLS AT DOCTORS’ DISPOSAL}

A shared accountability regime assumes that doctors would apply collective action to improve quality and efficiency. The SGR system was intended to impose a global budget on physician services, by automatically cutting reimbursements when expenditures exceed the target amount. In the aggregate this mechanism should have created an incentive for doctors to reduce growth in expenditures, but in practice, with individual doctors acting in their own interest, the system could not work.

As MedPAC has observed, "The SGR system has several flaws.",32 One, MedPAC notes, is the SGR's failure to address "inherent inflationary incentives" built into fee-for-service payment: Medicare's fee schedule pays

for the discrete services a physician furnishes-visits, imaging studies, laboratory and other diagnostic tests, and procedures. Such a small unit of payment gives physicians a financial incentive to increase the volume of services they furnish. Most beneficiaries have supplemental coverage that shields them from the costs of services, which contributes to the problem. ${ }^{33}$

Studies have shown that physicians do in fact act upon this incentive, and that "reduced fees are likely to be met by a combination of an increase in volume and a shift in the mix or intensity of services furnished to Medicare beneficiaries" ${ }^{\prime 34}$ as physicians seek to maintain a target income-the so called "income effect."

The other flaw identified by MedPAC is the SGR's "lack of differentiation" among physicians.

The SGR treats all physicians-regardless of their individual volume-inducing behavior-and regions of the country alike. Across-the-board cuts fall particu-

32. Medicare Payment Advisory Commission, Assessing Alternatives, supra note 13 , at 13 .

33. Id. at 14 .

34. Memorandum from Volume-and-Intensity Response Team, Office of the Actuary, Health Care Financing Admin., to Richard S. Foster, Chief Actuary (Aug. 13, 1998) (on file with The Indiana Health Law Review), available at http://www.cms.hhs.gov/ ActuarialStudies/downloads/PHysicianResponse.pdf (last visited May 15, 2010) [hereinafter Memo from Volume-and-Intensity Response Team]. 
larly hard on specialties that have less opportunity to inflate the volume and intensity of the services they provide and on regions of the country that have demonstrated more efficient practice patterns...At the same time, the SGR treats all volume increases the same, even though some may be desirable, such as those that improve quality or that substitute for more expensive nonphysician services. ${ }^{35}$

"Ideally, an expenditure target would provide individual physicians with an incentive to control the volume of services," 36 MedPAC notes. "But under the SGR, an efficient physician who reduces volume does not realize a proportional increase in payments. In fact, that physician loses twiceonce by reducing billed services and once through reduced future fees.",37

Under a shared accountability system, ideally these incentives should be reversed. The overarching incentive created by the ACO regime is for doctors to cooperate among themselves and with other providers to generate a positive update. The localized ACO gives doctors a realistic opportunity to cooperate in quality and efficiency efforts because of the small number of physicians and other providers in the pool. ${ }^{38}$

Cooperative efforts must be organized. Legislation establishing the ACO regime could provide for creation of a convening entity for each ACO, or leave it to the hospitals and physicians involved to decide on their own whether or how to coordinate their activities. For the latter approach, Congress could simply devolve the SGR structure to a lower level, and couple it with incentive pools. In the PGP demonstration, it was not necessary for legislation to establish governing structures for the accountable organizations-it simply set the ground rules for payment. In one case, a group of doctors constituted themselves on their own initiative (the Middlesex Health System) and went to work. ${ }^{39}$ In other cases, existing group practices joined the project. But in all cases, each doctor group organized its own care coordination processes. To the extent that the payment structure applies parallel efficiency and quality standards, and rewards, to both the hospital and the extended medical staff, these sometimes antagonistic parties should be able to act in concert.

Any legislation requiring or permitting ACOs would need to provide

35. Medicare Payment advisory Commission, Assessing Alternatives, supra note 13 , at 14 .

36. Id.

37. Id.

38. See Mancur Olson, The logic of Collective Action: Public Goods and the THEORY OF GROUPS 33-36 (Harvard University Press 1971).

39. Michael Trisolini et al., Medicare Physician Group Practices: Innovations in Quality and Efficiency, 41 THE COMMONWEALTH FUND REPORT viii (2006). 
for exemptions from regulations for cooperative activity consistent with the purpose of a shared accountability regime. Arguably, the sharing of savings could violate the anti-kickback statute ${ }^{40}$ or the civil monetary penalty statute ${ }^{41}$ and sharing of resources such as electronic medical records between a hospital and physicians could violate the physician self-referral law (known as the "Stark Law"). ${ }^{42}$ It should be noted, however, that the HHS Inspector General has approved such arrangements when they are made in the spirit of improving the quality and efficiency of care. ${ }^{43}$

The tools available to doctors would fall roughly into two categories, regulatory and clinical, although the self-regulatory nature of much of the health care system tends to blur the lines between the two.

By regulatory approaches, we mean that doctors could influence policymaking that would tend to improve quality and efficiency. Essentially these involve doctors lobbying state policymakers to institute reforms. Three such approaches come to mind:

- Limiting system capacity. Because heath care costs rise with increased capacity, the quickest and easiest way to lower costs is to lower capacity when resources exceed the level necessary to safely provide medical care. ${ }^{44}$ Possible reference points for the appropriate resource level would include those of the Dartmouth-identified "benchmark" regions and of an integrated delivery system, such as Kaiser Permanente. ${ }^{45}$ Two regulatory strategies suggest themselves: (1) Urging state Health Planning Agencies to restrict, or limit growth of, facilities within their jurisdiction; or, in states without certificate-of-need laws, urging legislatures to enact them. (2) Urging state officials to limit capacity in state-owned or funded facilities; for example, to reduce bed capacity in public hospitals, or to cut back non-essential residency programs at state university medical centers.

- Stricter quality enforcement. Where there is no collective accountability for quality, a "code of silence" as to poor performers can

40. 42 U.S.C. $\S 1320 \mathrm{a}-7 \mathrm{~b}$.

41. 42 U.S.C. $\S 1320 \mathrm{a}-7 \mathrm{a}$.

42. 42 U.S.C. $\S 1395 \mathrm{nn}$.

43. See, e.g., W. Clifford Mull, Office of Inspector General Gives Gainsharing Arrangements a Yellow Light, http://www.walterhav.com/library/News_Articles/ Gainsharing\%20Article.pdf (last visited Nov. 16, 2009); Nixon Peabody Health Law Alert, Federal Government Clearing the Way for E-Prescribing and Electronic Medical Records, Nov. 1, 2005, http://www.nixonpeadbody.com/publications/hla_11-12-5.pdf.

44. Elliott S. Fisher et al., Associations Among Hospital Capacity, Utilization, and Mortality of US Medicare Beneficiaries, Controlling for Sociodemographic Factors 34 HEALTH SERV. RES. 1351, 1351-62 (2000).

45. David Goodman, et al., Benchmarking the US Physician Workforce: An Alternative to Needs-Based or Demand-Based Planning, 276 JAMA 1811, 1811-17 (1996). 
thrive. ${ }^{46}$ But when every provider's compensation is dependent upon achievement of quality outcome goals, the incentive is to remove poor performers from the accountable unit. Among the strategies available are: (1) more rigid enforcement of hospital standards by state surveying agencies; (2) stricter discipline imposed upon doctors by state medical boards and Quality Improvement Organizations; (3) tougher maintenance of certification requirements for practicing doctors, or higher thresholds for initial licensure. In some cases this would be easy, as where a doctor already has a reputation for impairment or incompetence, and can be removed from the pool by revoking his hospital admitting privileges and/or instituting license revocation proceedings.

- Public health approaches. To the extent that performance goals include general health measures, and the health status of a geographically compact and cohesive population is being measured, doctors can add public health strategies to their lobbying priorities. For instance, doctors could lobby local governments to increase access to grocery stores and decrease access to fast food outlets; to raise alcohol and tobacco taxes; and to plan walkable communities in which seniors are likely to remain active.

There are several clinical approaches by which doctors could act collectively to improve quality and efficiency.

- Organized forbearance in volume and intensity of care. The cornerstone of the collective efficiency effort is cooperation in holding down utilization beyond the point where marginal expenditures yield no further benefit. Some outlier doctors may be known to perform procedures at an eyebrow-raising volume ${ }^{47}$ and their immediate removal from the pool could be a very quick avenue to a noticeable increase in the group's conversion factor. In the accountable care organization, there need be no insurer or utilization review process looking over doctors' shoulders-the doctors themselves must draw the line between necessary and unnecessary care. They must also enforce compliance, because if any doctors "defect" from the agreement and bill for more services than are necessary, they reduce the conversion factor for the unit as a whole and force the rest of the doctors to follow suit- the same dynamic pre-

46. See generally Rosemary Gibson and Janardan Singh, Wall of Silence: The UNTOLD STORY OF THE MEDICAL Mistakes that KILl AND INJURE MILlions OF AMERICANS (Life Line Press 2003).

47. See, e.g., Deborah Gates, Lawsuit Filed in Stent Surgeries: 24 Plaintiffs Seek More than $\$ 30 \mathrm{~K}$ Per Count, The Daily Times (Salisbury), Jul. 22, 2008, at 1 (providing a real-life example in relation to stent surgeries). 
vailing in the current, nationwide SGR regime. To maintain compliance, doctors in the ACO will probably want to use some of the same techniques that insurers use to identify outlier doctors. Use of such techniques in the ACO, however, will be different in that doctors themselves must be satisfied as to the validity of methods (e.g. physician profiling software) ${ }^{48}$ and the fairness of any process used to identify outlier colleagues.

- Clinical integration. The cornerstone of an ACO's collective quality effort would be clinical integration, argues Thomas Rundall. This would involve "providers working together in an interdependent fashion so that they can pool infrastructure and resources; and develop, implement [and] monitor protocols, 'best practices,' and various other organized processes.",49 Examples cited by Rundall include coordination across entities for an entire episode of care, creation of disease registries and other chronic care programs, facilitation of electronic health record (EHR) acquisition, and even supply chain management. Fisher and colleagues note that one of the advantages of

larger organizations relates to their capacity to invest in improving quality and lowering costs. Most physicians remain in solo or small group practices and have neither the capital nor organizational capacity to invest in health information systems, the implementation of care management protocols, or ongoing quality improvement initiatives. Hospitals or large medical groups are much better positioned to invest in such systems and to provide financial and technical support to physicians aligned with their institution. ${ }^{50}$

- Infrastructure development. Rundall also argues that the wellorganized ACO would "develop mechanisms to monitor and control utilization of services and enhance quality and efficiency"51 including feedback on performance, peer-to-peer counseling, and tools and processes to help physicians improve quality. The necessary infrastructure to accomplish this, says Rundall, is a paid professional staff led by a medical director that could collect and

48. See Lewis Sandy, The Future of Physician Profiling. 22 J. of AMBUlatoRy CARE MGMT. 11, 11 (1999).

49. Thomas Rundall, University of California, Berkeley, Accountable Care Organizations: Key Characteristics and Activities, Presentation at Academy Health Annual Research Meeting (Jun. 4, 2007).

50. Fisher ,et al., Creating Accountable Care Organizations, supra note 12, at w53.

51. Rundall, supra note 49. 
analyze data, as well as shared nurse care managers to coordinate the education and care of patients.

- Exclusivity. Ultimately, the ability of the ACO to enforce improvements relies upon the power to exclude physicians who do not act in the spirit of the cooperative venture. Speaking of an antecedent of the ACO, the independent practice association, James Robinson has written,

Credentialing on clinical, cultural, and economic grounds seeks to ensure that the physicians participating in the health plan or medical group embrace the organizational goals of appropriate care, and hence avoid both over- and undertreatment, independent of explicit payment incentives. The creation of physician networks with limited participation creates a supplementary nonprice mechanism through the potential threat of termination. Preemployment screening and the threat of termination are core principles of every employment situation and are applied in a looser fashion to networks of quasi-independent practitioners. $^{52}$

Presumably any ACO must have the power to expel a doctor, although the means of doing so and the consequences for the doctor-and patients - must be carefully considered. Due process for the physician is a must. If a hospital is the locus of an ACO, and admitting privileges are revoked, would this constitute expulsion from the ACO? Could a doctor be expelled from the ACO pool without having credentials revoked? How would Medicare payment be affected if a doctor does not belong to ACO? If the doctor were simply kicked into a residual pool, rather than barred from participating in Medicare, the doctor presumably would be paid less, losing opportunities for shared savings or other positive updates to the conversion factor. But that doctor's patients would lose the benefits of clinical integration that the ACO structure is meant to confer on patients. Determining the consequences of ACO expulsion will require a careful balancing of the doctor's right to continue practicing, the patient's right to remain loyal to the maverick doctor, and the need to keep patients within a care coordination regime.

52. James C. Robinson, Theory and Practice in the Design of Physician Payment Incentives, 79 MILBANK Q. 149, 165 (2001). 
It could be stressful for doctors to crack down on colleagues who are in the bottom tier of efficiency and quality. But if certain doctors would be a drag on the pool's financial performance, the ACO's physicians will have to make a choice: subsidize the poor performers' continued practice by accepting a lower conversion factor for their fees, and explain to the community why the ACO's quality ratings remain sub-par; or expel the doctors, a move that would be in the ACO's financial interest and the public's interest as well.

A middle-ground strategy would be to identify poor performers and allow them a chance to remediate. This would be less gut-wrenching than simply expelling poor performers, but would require the majority of doctors to suffer financially for a time in the name of group solidarity.

Efficiency and quality rankings would not be the only potential cleavage among doctors in an ACO. Those doctors who profit from ancillary services or ownership of surgical facilities could also be seen as taking more than their fair share of the ACO's SGR pool. ${ }^{53}$ Doctors would have to carefully scrutinize these physician-owned facilities to determine whether they add to or subtract from the ACO's overall quality and efficiency scores. Doctors would also have to scrutinize the utilization patterns of their investor-physician colleagues.

In any event, doctors would enjoy a major advantage under the ACO regime relative to other cost-containment regimes: doctors would be empowered to choose the cost containment strategies themselves. Rather than an insurance carrier or bureaucracy scrutinizing their activities, doctors could police themselves. They would have to reach consensus on the validity of any physician profiling methods, recertification programs, utilization review processes or other techniques-none would be imposed on them by outsiders. All that would be imposed on them are performance goals based on the experience of their peers in high-performing regions; it would then be up to each local medical community to determine how they can achieve the benchmark performance level.

\section{FOUR MODELS OF SHARED ACCOUNTABILITY}

This part of the paper posits four types of shared accountability regimes. It is not the purpose of this paper to propose or advocate models, only to assemble features of existing law, existing pay-for-performance demonstration projects, and ideas floated by commentators into somewhat more concrete descriptions of possible models, and then speculate how such models might operate in practice. The discussion assumes the following:

53. See, e.g., Medicare: Physicians Who Invest in Imaging Center Refer More Patients for More Costly Services: Hearing Before the Subcomm. on Health of the H. Comm. on the Ways and Means, 103rd Cong. 1-8 (1993) (statement of Janet L. Shinkles, Director, Health Financing \& Policy Issues, Human Resources Division). 
that some type of SGR mechanism would set targets for global expenditures; that the current methods of calculating fees would remain in effect; that the accountable unit would share in savings through mechanisms similar to those employed in the Physician Group Practice demonstration; and that additional funds could be added to the accountable unit's pool for distribution to reward achievement, based upon currently existing outcome or population health measures.

It should be noted at this point that Medicare's SGR does not represent the only possible model for a global budget under which an ACO could function. For instance, President Bill Clinton's 1993 health care reform package proposed all-payer global budgets at the state or local lev$\mathrm{el},{ }^{54}$ and a similar model prevails in Germany. ${ }^{55}$ In the event that the United States adopted such cost containment techniques, the ACO model would provide a superior method of delivering care to the non-integrated bodies of physicians receiving fees under the 1993 Clinton or current German model.

\section{A. State Level}

The simplest model of shared accountability would be to devolve the SGR pool to the state level. In this iteration, the conversion rate for physician fees would be calculated as they are under current law, but at the state level. In states where expenditures come in below the target (assuming steady or improved performance on quality and patient-centeredness measures) physicians would receive a positive update. ${ }^{56}$ In states were expenditures exceed the target, physicians would receive a negative update unless improved performance on the quality and patient-centeredness dimensions cancelled it out.

As Frank Opelka has noted,

A regional spending target will face technical and political obstacles. Regional proposals... will run into the obstacle that most physicians are currently independent. Regional spending target programs will have major challenges in bringing clinical disciplines together except in existing integrated systems. Each region will need to compare its current performance against benchmarks and seek opportunities for improvement...Toolkits for regional entities to imple-

54. Health Security Act, H.R. 3600, 103d Cong. (1st Sess. 1993).

55. Richard Knox, Keeping German Doctors On A Budget Lowers Costs, NPR, Jul. 2, $2008 \mathrm{http}: / / \mathrm{www}$. npr.org/templates/story/story.php?storyld=91931036.

56. See Medicare Payment ADVISORY COMmission, RePORT to the CONGRESS: MEdicARe PAYMENT Policy 172 (March 2005) [hereinafter MEDICARE PAYMENT AdVISORY COMmission, MEdicare Payment Policy]. 
ment the program will facilitate the implementation and likelihood of overall success. 57

The following vignettes imagine scenarios that could ensue under this model:

- East Dakota is one of the states identified by Dartmouth researchers as already providing high quality care at relatively low costs. Analysis of Medicare claims data reveals that East Dakota already meets quality benchmarks, and growth in costs is within the limits prescribed by the 1997 SGR formula. It is immediately apparent to the Medical Society board members that, had East Dakota been in its own SGR pool heretofore, its doctors would have received positive updates rather than negative updates. The board decides that, since the state's health care system is working well, no organized response to the ACO legislation is necessary; doctors will continue to practice as they have previously and will continue with ongoing quality improvement efforts.

- New Guernsey is a state with relatively high quality rankings but with high costs as well. In New Guernsey, the average Medicare beneficiary pays about $\$ 900$ in Part B coinsurance, well above the national average of about $\$ 700$. An affluent state with many pleasant, leafy suburbs, New Guernsey has attracted a large contingent of medical specialists. While proud of its talented physician workforce, the state Medical Society's analysis of Medicare data reveals that the high intensity of specialty care given to chronically ill Medicare beneficiaries cannot be linked to better outcomes. Moreover, New Guernsey's rate of certain invasive medical procedures is far higher than the national average. The Medical Society asks the state legislature to order a hiring freeze for over-represented medical specialties at the state's academic medical centers pending a study to determine the optimal specialty distribution of the state's physician workforce. The Medical Society also commissions the state's QIO to conduct a case/control study of patients with conditions that receive disproportionate rates of surgery in New Guernsey relative to other states, and separate, specific probes of hospitals and surgeons that perform unusually high volumes of such procedures. It expects that unnecessary utilization will be eliminated, and the remaining physicians will share larger slices of the Medicare pie.

57. Frank Opelka, The Sustainable Growth Rate: Bringing the SGR To Individual Providers, Health AfFaIRs BlOG, Feb. 20, 2008, http://healthaffairs.org/blog/2008/02/20/ the-sustainable-growth-rate-bringing-the-sgr-to-individual-providers/. 
- West Carolina is a state with poor quality ratings and, while not ranked near the top in spending, seems to be spending more than it should given its outcomes. Observers note that the state Board of Medicine has consistently low rankings in disciplinary actions per 1,000 doctors, and a large number of hospital beds per capita seems to be driving a high number of hospital days during chronically ill Medicare beneficiaries' last two years of life, many of them in ICUs. The Medical Society mounts a comprehensive quality improvement campaign. One element, inspired by Jack Welch's strategy of forcing out the lowest performing managers, urges doctors to provide confidential evaluations of peers and hospitals to regulatory authorities. The Board of Medicine is given an infusion of resources to pursue disciplinary proceedings. The state Health Planning Agency is urged to convene a hospital closing commission to reduce bed capacity at the least effective facilities. With both state residents' self-reported health status and public health expenditures ranking low, the Medical Society persuades state legislators that the most cost-effective way of improving health outcomes is not through more health care delivery spending but through more public health and prevention efforts. The Medical Society expects that its commitment to a new paradigm will improve the Medicare population's health, recruit new, talented doctors to the state, and, not incidentally, bring P4P bonuses to its members.

\section{B. Local Level: Extended Hospital Medial Staff/Multi-Specialty Group Practice}

The most administratively complex shared accountability model would be one with multiple ACOs formed at the local level. In the hypothetical scheme discussed below, physicians would initially be assigned to a pool based upon the "extended hospital medial staff" (EHMS) - empirically observed referral patterns derived from the methodology described by Fisher and colleagues. Doctors would then be free to opt out of their assigned pool and affiliate with another pool, should it accept the doctor; or to carve out an entirely new pool based on the multi-specialty group practice model. The latter could be an existing multi-specialty group entity, or a newly created independent practice association.

Each ACO would also be assigned, for administrative purposes, its doctors' patients. Those patients would form the population on which the ACO's expenditure pool would be risk-adjusted and on which performance outcomes for the ACO are measured. It would not, however, constitute a network to which patients are bound, since Medicare beneficiaries are free to see any doctor. This means that doctors would need to persuade assigned patients to accept their referrals, and follow the patients' progress.

Once a physician must cast his lot-and future updates - with a pool, 
he may decide to rethink his affiliation. A doctor may suspect that the quality of Hospital A is poor, or that the doctors who admit there treat patients too aggressively, and decide to switch his affiliation to Hospital B. Allowing doctors to "vote with their feet," provided that they do in fact restrict their referrals to the provider community associated with Hospital B, could be beneficial to patients and to Medicare. Doctors would refer patients to providers they believe to be effective and efficient. Doctors unable to switch to a better hospital, because they do not have admitting privileges, would have an incentive to improve the quality and efficiency of the hospital and pool in which they remain, by, for instance, becoming active in hospital committees.

Doctors who felt that they could not improve their default pool's performance might opt to form or join a multi-specialty group practice whose patients would comprise a separate pool. Many in the health policy community believe that such an arrangement would benefit patients. But patients could not be restricted to receiving their care from doctors in the group, given the distinction between FFS Medicare and Part C plans, so the pool would be an odd neither-fish-nor-foul creature. As MedPAC noted,

\begin{abstract}
CMS... would have to devise a way of attributing services received by individual beneficiaries to groups without locking beneficiaries into receiving care from any specific group. Some health plans have developed algorithms that attribute patient care to particular groups on the basis of the percentage of care they receive from any one group. Medicare might adopt such a methodology for its own use, but the process would likely be complex and raise many questions. ${ }^{58}$
\end{abstract}

Nonetheless, if such an option would encourage competition and integration of delivery systems while still letting doctors maintain the autonomy they enjoy in the FFS system, the option might be worth the trouble.

The following vignettes illustrate how providers could react to a system of local ACOs:

- Dr. Smith has admitting privileges at both Northside Hospital and Southside Hospital. Because the majority of his Medicare patients have been treated at Northside Hospital, he is given a default ACO assignment to that institution's EHMS. Upon reflection, Dr. Smith realizes that he has referred patients to Northside primarily for reasons of convenience, not because he is convinced that its clinical

58. Medicare Payment Advisory Committee, Medicare Payment Policy, supra note 53, at 172 . 
quality is superior to Southside. He switches his assignment to Southside based on his belief that performance bonuses earned by the Southside EHMS will more than offset his travel costs.

- Same scenario as above. A number of stakeholders in Central City have expressed concern about the cost and quality of care at Northside Hospital, which has also had a poor relationship with doctors in recent years. Board members of the hospital are concerned that the advent of ACOs could cause doctors to take their Medicare patients away from Northside en masse. The Northside board asks the hospital CEO to resign and appoints a management committee that includes doctors to iron out problems and develop a Physician/Hospital Organization (PHO) structure through which doctors and hospital administrators can collaborate to improve quality and efficiency.

- Same scenario as above. Because risk adjustment criteria increase the pool of money for ACOs with diabetic patients, and shared savings from avoided hospitalizations leave more money in the pot for doctors, the Northside PHO decides that the large number of diabetic Medicare beneficiaries living at the north end of Central City could make diabetes care a profitable area of concentration. The PHO assesses doctors a small amount of money to fund a PHOwide diabetes registry and care coordination team. The PHO then advertises its expertise and resources in the senior community to persuade diabetic patients to choose Northside-affiliated doctors. As employers and private insurers in Central City see improved outcomes, they agree to make additional payments to the Northside PHO to enroll their insureds into the chronic care program.

- Same scenario as in the first two bullet points, except that the leadership of Northside Hospital is unable to convince enough doctors to remain in its EHMS for the hospital to remain viable. Central City's mayor and civic leaders broker an agreement by which Northside and Southside hospitals merge. Only Southside will provide inpatient care, as it has clearly proven its superiority in inpatient quality. Northside will remain open only to provide outpatient care and emergency care. The move is applauded by insurers and the business community, who long felt that that Central City had excessive hospital bed capacity and that operations should have been consolidated at Southside.

- Dr. Jones is medical director of Medical Faculty Associates, a multi-specialty group practice that is considered Central City's finest. Because Medical Faculty Associates is based at Central City University Hospital, all members of her practice have been assigned to an EHMS pool that includes many other doctors who send patients to that hospital. Convinced that her medical group can outperform other doctors in the EHMS, Dr. Jones persuades her colleagues to 
file papers with CMS carving out their group practice as a separate ACO with a separate pool.

- Dr. Wilson is a member of a PHO described above. The PHO doctors adopt guidelines for the frequency of office visits for controlled hypertension, and creates a patient registry for diabetic patients. It is agreed that each doctor will waive beneficiaries' coinsurance for certain recommended treatments for diabetics as part of a campaign to eliminate preventable complications. Strapped for cash, Dr. Wilson decides to disregard the guidelines on hypertension to generate extra office visits, and to collect coinsurance on all services to diabetics. Staff hired to administer the PHO discover Dr. Wilson's conduct and he is confronted by a delegation of peers. Dr. Wilson complains that the new Medicare system is unfair and impairs his ability to earn a fair income. The PHO votes to expel Dr. Wilson.

- Eventually, Central City is served by four ACOs. Each ACO "brands" itself and advertises its network to Medicare beneficiaries as consisting of high-quality providers. Central City's Medicare population is, in essence, served by a variant of the "managed competition" model envisioned by Alain Enthoven.

- Puritan Hospital, situated in a rural state without certificate-of-need laws, has faced financial pressures from physician-owned cardiac and orthopedic hospitals taking away profitable procedures that have cross-subsidized less remunerative facilities such as burn care and emergency care. Additionally, doctors affiliated with the specialty hospitals have been able to avoid emergency room coverage. Under the algorithm for EHMS assignments, the doctors practicing at the specialty hospitals are assigned to an ACO based at Puritan Hospital. Because of the pool structure, the specialty hospital doctors now have a financial stake in the quality and efficiency of care delivered to the county's entire Medicare population, not just their own patients: bonuses to the pool as a whole depend on reducing readmissions and 30-day mortality at all three hospitals. The county medical society mediates an agreement between Puritan Hospital and the specialty hospital doctors to ensure that cardiac and orthopedic procedures are performed at the facility where efficiency and quality is maximized and that the specialists resume their emergency on-call duties at Puritan. The Medical Society also initiates talks with walk-in clinics at local retail stores, which have also been assigned to the ACO, to ensure proper coordination of Medicare patients' care.

One can also imagine the virtual integrated delivery systems formed for Medicare beneficiaries serving as platforms for activities entirely unrelated to Medicare. Private insurers could piggyback pay-for-performance programs on an ACO structure. (Indeed, the reverse could happen too- 
doctors included in a private insurer's high-quality, high-efficiency network could perceive an advantage to using the insurer's designation to sort themselves into an ACO). ACOs could also become purchasing cooperatives for obtaining malpractice insurance, perhaps at significantly lower rates if insurers perceived their clinical integration as lowering risks.

The prospect that an Enthoven-model competition among ACOs could eventually emerge recalls the threshold question, "accountable to whom?" While ultimately the purpose is to make providers accountable to patients, in its initial formulation, the accountability flows to CMS. But if something approaching managed competition is possible in an ACO regime, it might be possible at some point for performance rewards to be dropped and replaced entirely by consumer choice. After some time, all ACOs would have performance records that consumers could easily compare. In an ideal scenario, the best systems would attract greater numbers of patients and would earn increased profits from higher volume, obviating the need to reward performance with higher per-unit pay. It should be noted, however, that many experts are skeptical that consumers do, or are ever likely to, scrutinize performance reports to this degree.

\section{Insurer-Convened $A C O$}

An Accountable Care Organization convened by a "Medigap" (Medicare supplement insurance) insurer would bear some superficial resemblance to "Medicare Select" networks formed to serve Medigap policyholders. ${ }^{59}$. Like Medicare Select, such an ACO would likely be built around a contracting hospital and would enroll beneficiaries into a networkoriented Medigap policy. Unlike Medicare Select, however, the primary purpose would be to save money through improved quality and efficiency, not through negotiated discounts.

A Medigap-centered ACO could be authorized by allowing a Medigap insurer to enroll some of its beneficiaries into a preferred provider network within Medicare and share in savings (with CMS and providers) that it can attribute to better-than-expected performance by its network. The insurer could then identify providers that, judging from its own experiences in the private market, could be expected to deliver high-quality, efficient care; or supply a common IT platform physicians that would assist them in this task.

- Midwestern Standard Insurance has found that of three competing hospitals in Middletown, Community General Hospital seems to deliver the best care to its enrollees at the lowest costs. It applies AHRQ's Inpatient Quality Indicators to Medicare claims data from the three hospitals and finds that Community General also seems to 
provide the best care to Medicare patients. Utilizing the methods developed by Dartmouth researchers it examines Medicare claims data to identify the de facto "extended medical staff" of physicians who refer to each of the three hospitals and then applies MACIEs to those doctors' patients' claims, and learns that this virtual group of physicians also provides superior ambulatory care to its patients. The insurer approaches the hospital leadership with a proposal that they jointly market a Medigap product through the existing physician "network." Doctors sign on to the arrangement in exchange for the insurer's promise to pay them, from the insurer's shared savings pool, end-of-year bonuses based on the number of Medicare patients in their practice.

- Same scenario as above, except that doctors are unwilling to sign onto any arrangement. But rather than abandon the project, Midwestern Standard enters into a contract with Community General only. The resulting Medigap product is marketed to beneficiaries based on the hospital's quality record of superior outcomes and a lower premium based on the EHMS physicians' efficiency. However, Midwestern Standard still promises, unilaterally, to pay doctors who are part of the de facto extended medical staff end-of-year bonuses so long as they continue to maintain the same level of quality and efficiency. After receiving the first year's bonuses, as well as many new patient referrals from the insurer, the physician community decides to formalize the arrangement.

- Same scenario as above. St. Aloysius Hospital, another hospital in Middletown, and its affiliated physicians, have noticed a drop in Medicare patient load since Community General began offering its Medigap product. St. Aloysius officials approach Prairie Standard Insurance about forming an ACO to offer a competing product. After performing the same research on Middletown health care that Midwestern Standard did, Prairie Standard officials conclude that adoption of electronic medical records and a concerted effort by St. Aloysius and its doctors to lower the intensity of care would likely enable the ACO to earn shared savings bonuses within two years. The hospital and nearly all its de facto EHMS doctors agree to form a PHO and contribute capital to purchase an EMR system.

Some would argue that a Medigap-convened ACO would amount to the "tail wagging the dog." Allowing such an option would, however, afford an additional opportunity for innovation in serving the Medicare population.

\section{A "Competitive Dynamic" Approach to Updates}

A fourth possible model for shared accountability is suggested by 
comments made by MedPAC commissioner Francis Crosson during that panel's discussion of the accountable care organization concept. After noting the unpopularity of the SGR, Crosson observed:

...the target or the use of targets is in the end going to be less important than the dynamic that is created by the payment system because the target really just addresses the amount that's paid ...

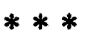

So I have less interest or concern about the target as a starting point and what that ought to be than the nature of the dynamic. I think I'll just give an example of what I think might be something that illustrates that...

[S]tarting with some basis for next year's payment that would be either based on reasonable input costs or perhaps, in some circumstances, less than that based upon what we think we can afford as a country, taking that number and perhaps modestly adjusting it regionally. Let's say we ended up with a number of 2 percent as a starting point, and we could arrive at that number by a number of different means.

But then... [physicians in geographic regions], group practices [or] accountable organizations which would include physicians and medical staff physicians in hospitals -- would essentially work sort of in competition with each other around that number. And there would be a range around that number of reward or loss based on that...you might end up with a 3 percent range on each side. And so you could have within each geography some entities that ended up with a couple of points minus [two] and some that ended up with 4 or $5 \ldots$

[A] system of slow inexorable competition with 2, 3, 
4, 5 percent differentials year-to-year [that] would, in fact, create the dynamics that we're interested in. ${ }^{60}$

In Crosson's view, "there is a current opportunity to investigate whether a subset of the national physician community, properly equipped and with proper incentives, could manage both the volume of services and the quality of services delivered to Medicare beneficiaries over time, within a fee-for-service setting." ${ }^{61}$ This discussion uses Crosson's concepts as a jumping-off point for envisioning informal or voluntary means by which doctors could compete, at the level of a geographic or other unit, for a limited pool of increased Medicare funding that would be apportioned based upon performance.

MedPAC Chairman Glenn Hackbarth recently noted that the SGR may be more useful as a "tool for altering the dynamic of the policy process than as a tool for directly improving how providers deliver services. An expenditure target alerts policymakers that spending is rising more rapidly than anticipated and leads to an annual debate over the update to the physician payment rate. That debate may also influence the behavior of providers: To avoid rate decreases, they could be compelled to support payment reforms that they might otherwise find objectionable." 62

In fact, the SGR has led to annual debates about updates, but the debates have not as yet led to payment reforms. Perhaps, as part of these debates, a "competition" of the type envisioned by Crosson could be kicked off either formally, through laws passed or position statements made by government officials, or informally, by position statements made by stakeholders.

One can picture several means by which some measure of competition could be formally initiated by government officials:

- The first such proposal along these lines emerged in the CHAMP Act, a bill passed by the House of Representatives in mid-2007. ${ }^{63}$ Section 304 of the bill would have provided a five-percent bonus

60. Transcript of Public Meeting at 25-28, 69, Medicare Payment Advisory Commission (Jan. 9, 2007), available at http://www.medpac.gov/transcripts/All_Medpac.final.pdf (last visited May 15, 2010).

61. Jay Crosson, An SGR Reform Proposal: The Impact Of A Payment Update Alternative For Multi-Specialty Group Practices, HeAlTH AFFaIRS BloG, Feb. 19, 2008, http:/healthaffairs.org/blog/2008/02/19/an-sgr-reform-proposal-the-impact-of-a-paymentupdate-alternative-for-multi-specialty-group-practices/.

62. Assessing Alternatives to the Sustainable Growth Rate System: Hearing Before the Subcomm. on Health of the H. Comm. on Energy and Commerce, 110th Cong. 2 (2007) (statement of Glenn M. Hackbarth, Chairman, Medicare Payment Advisory Commission), available at http://energycommerce.house.gov/images/stories/Documents/Hearings/PDF/ 110-he-hrg.030607.Hackbarth-Testimony.pdf (last visited Ma y 15, 2010).

63. Children's Health and Medicare Protection Act of 2007, H.R. 3162, 110th Cong. (1st Sess. 2007). 
to physicians in counties or equivalent areas in the United States in the lowest fifth percentile of utilization based on per capita spending. This proposal tracks closely with the one Crosson informally proposed during the MedPAC discussion in that it awards a higher update to physicians in higher-performing regions. This proposal, while intriguing, was deficient in that it did not require maintenance of quality or patient experience metrics.

- A policy option identified by the Commonwealth Fund Commission on a High Performance Health System would eliminate payment updates to providers in regions with per-beneficiary spending exceeding the $75^{\text {th }}$ percentile (defining regions as metropolitan areas or combined rural areas in each state); update payments on a sliding scale for regions between the $50^{\text {th }}$ and $75^{\text {th }}$ percentiles; and award full updates only in regions with spending at or below the $50^{\text {th }}$ percentile. The Commission estimated savings to Medicare of $\$ 157.8$ billion over ten years. ${ }^{64}$

- Congressional budget resolutions could state, in advance, the amount of money to be allocated for a physician pay increase, and urge that the updates be distributed on the basis of merit rather than across the board, thereby challenging physicians to improve performance.

- Leaders of congressional committees with jurisdiction over Medicare, or officials of HHS, could announce that they will support only a limited increase and set forth criteria by which the additional dollars should be distributed.

One can also imagine a process initiated by stakeholders:

- Organizations representing Medicare beneficiaries, perhaps allied with business groups or insurers, could propose criteria for awarding pay increases, and pledge to lobby for updates limited to qualifying units.

- Physician organizations in states with high quality, efficient health care could break away from national physician groups to negotiate a "separate peace" in which they receive generous updates but others do not. Indeed, such a dynamic was reportedly at work in the lobbying by doctors from Minnesota and Wisconsin for inclusion of Section 304 in the CHAMP Act. ${ }^{65}$

- CMS could formally invite groups of physicians to carve themselves out of the nationwide SGR pool into smaller pools on a pilot-

64. Cathy Schoen, et al., Bending the Curve: Options for Achieving Savings and Improving Value in U.S. Health Spending, 80 THE COMMONWEALTH FUND 1, 59 (2007).

65. CHAMP Would Provide 5 Percent FFS Bonus for Efficient Providers, INSIDE CMS, Aug. 9, 2007, 2007 WLNR 15338105.. 
program basis. Crosson has proposed such a mechanism, in which physicians in multi-specialty group practices who care for Medicare beneficiaries on a fee-for-service basis could apply for inclusion in a separate pool upon "demonstrated ability to use evidence-based medicine and other systematic processes of care; electronic medical information capabilities; the use of systematic quality of care improvement techniques; responsible physician compensation practices; and the willingness to be part of a collective, transparent monimonitoring and improvement process.",66

As noted earlier, there are a number of population-level measures that can be used to evaluate the efficiency and quality of health care. Officials or stakeholders could construct grids plotting each state's efficiency measures on one axis and quality measures on another axis. The resulting matrix, if plotting increased efficiency from left to right on the $\mathrm{x}$ axis, and increased quality from top to bottom on the y axis, would identify candidates for merit increases in the upper right quadrant. Thus, to apply Crosson's example assuming a base level of a positive two-point update, a first iteration of a competitive dynamic process could make states in the upper right quadrant eligible for three point updates, and states in the lower left quadrant relegated to one-point updates. In a second iteration, doctors who believed that they could outperform same-state peers might feel challenged to form some type of cohesive group that would cooperate to improve performance and set itself apart from the larger group to earn a more favorable update.

The following illustrations draw upon examples described earlier in this paper. Imagine that the state of New Guernsey falls in the middle and has been identified by policymakers or stakeholders as deserving of a two percentage point update.

- Representatives of the New Guernsey State Medical Society organize a meeting with their state's congressional delegation. The doctors are upset because their quality ratings place them in the upper tier on that dimension yet they are being denied a three-point update due to inefficiency. They inform their representatives that if they do not receive the three-point update, doctors may have to stop seeing Medicare patients. Senator Burton responds by noting that in states receiving three point updates, Medicare beneficiaries pay substantially less in coinsurance, and that if New Guernsey doctors received the three-point update, his constituents would pay the highest average coinsurance among the 50 states. The congression-

66. Crosson, supra note 58. See also Laura A. Dummit, Updating Medicare's Physician Fees: The Sustainable Growth Rate Methodology, 818 NAT'L HEalTH Pol'y F.1 (2006); Mark McClellan, Medicare Payment for High-Quality, Efficient Care, Presentation at Fifteenth Princeton Conference on Health Care Economics and Policy (May 28, 2008). 
al delegation tells the doctors to develop a plan for increased efficiency, and pledges that if the doctors can show progress in ing costs while maintaining quality outcomes, they will fight for a full three-point update the following year.

- Dr. Brown, the solo practitioner in Central City who has been consistently named to the top "tier" of insurers' provider networks assembles other similar practitioners to form a provisional IPA. The doctors sign onto a public letter to the state's congressional delegation and beneficiary advocates promising that they can outperform the state's other doctors and asking that if they succeed, that they be carved out for a higher update the following year. Senator Burton secures passage of a bill recognizing the IPA as an accountable care organization and ordering CMS to assign the doctors' current and future Medicare patients to the ACO and to collect risk-adjusted statistics on utilization and outcomes for the IPA's patient population over the coming year so that the doctors can be considered for a separate update calculation.

The competitive dynamic approach carries many intriguing possibilities. Because of its informality, it could be used immediately-beginning with the current legislative cycle surrounding a "fix" for the SGR. It can utilize existing measures for assessing efficiency, quality, and patientcenteredness (although there likely would be disagreement over exactly which measures to use and how to weight them). By localizing Medicare policy, it would air the interests and viewpoints of local stakeholdersincluding beneficiaries - who are probably unaware of how their local medical community measures up in terms of the quality of care they receive and its cost, which is reflected most notably in coinsurance and which varies greatly. It has the potential for empowering grass-roots groups of beneficiaries to support or oppose their own doctors' pay updates based on the costs and quality of medical care on a community-by-community basis.

It is worth noting here that two health policy initiatives embraced by the Obama administration in early 2009 encourage virtual integrated delivery systems and may constitute small steps in the direction of accountable care organizations.

The first was the Health Information Technology for Economic and Clinical Health ("HITECH") program enacted in the American Recovery and Reinvestment $\mathrm{Act}^{67}$ to spur adoption of electronic health records. Congress apparently followed the urging of HIT innovators to use communities as the locus of new "Health Information Technology Regional Extension

67. American Reinvestment and Recovery Act of 2009, Pub. L. No. 111-5, 123 Stat. 115 (2009). 
Centers." ${ }^{.68}$ This approach follows the model of the Massachusetts eHealth Collaborative, which built its three demonstration projects around hospitals and associated PHOs or IPAs. Massachusetts eHealth Collaborative was funded by Blue Cross/Blue Shield of Massachusetts, which as noted earlier instituted an "Alternative Quality Contract" initiative, a private-sector variation on the ACO theme.

The HITECH program provides seed money and enhanced Medicare payments to physicians for a limited period, but contemplates the selfsufficiency of each extension center when that period expires. The HITECH systems could theoretically achieve cost-neutral efficiencies on two dimensions. First, efficiency savings could be reaped by physicians themselves, in which case physicians would be willing to pay to sustain the EHR system. This seems unlikely-- most observers believe that HIT efficiency savings are external to physicians. ${ }^{69}$ The second source of savings would be savings to payors from avoidable injuries, hospitalizations or duplicative tests which, to be plowed back into HIT operating expenditures, would have to be shared with providers in some type of ACO arrangement.

The other new initiative is the call in President Obama's budget document for providers to assume shared accountability for hospital readmissions. $^{70}$ The document is vague but appears to be endorsing two MedPAC recommendations on this subject. ${ }^{71}$ One is to "bundle" payments to a hospital and other providers who take care of a patient upon discharge; the other is to penalize hospitals for what is deemed an excessive volume of avoidable readmissions. Both encourage greater coordination of care following a hospital discharge. These initiatives do not envision shared accountability on the scale of an ACO but, like the HIT program, nudge providers in the direction of integration by forcing them to build connections.

\section{CONFLICTS LIKELY TO ARISE IN A SHARED ACCOUNTABILITY REGIME}

The discussion above describes conceptually how a well-designed ACO regime might move to an equilibrium point at which each system ac-

68. Farzad Mostashari \& Micky Tripathi, Achieving Meaningful EHR Use: Leveraging Community Structures, IHEALTHBEAT, Feb. 10, 2009, http://www.ihealthbeat.org/Perspectives/ 2009/Achieving-Meaningful-HER-Use-Leveraging-Community-Structures.aspx..

69. Congressional BUdGet OfFICE, EVIDENCE ON THE COSTS AND BENEFITS OF HEALTH INFORMATION TECHNOLOGY 17-18 (2008), available at http://www.cbo.gov /ftpdocs/91xx/ doc9168/05-20HealthIT.pdf.

70. Office of MgMt. \& Budget, Executive Office of the President, A New Era of RESPONSIBIITY: RENEWING AMERICA'S PROMISE (2009) available at http://www.gpoaccess.gov/ USbudget/fy10/pdf/fyl0-newera.pdf.

71. See Medicare Payment Advisory Commission, Report to the Congress: REFORMING THE DELIVERY SYSTEM (2008), available at http://www.medpac.gov/documents/ Jun08_EntireReport.pdf. 
tor's financial incentives align with efficiency and quality. Needless to say, any flaws in the reward and punishment structure could result in unintended negative consequences.

Moreover, even a perfectly-designed structure would involve a painful transition period of "creative destruction" during which many conflicts would arise. A system of mandatory, local-level ACOs based initially upon extended hospital medical staffs would have the greatest potential for revamping the delivery system but would also carry with it the maximum opportunities for conflict.

Many consequences could flow from the individual doctor's choice of ACO with which to affiliate. There may be some hospitals with such poor reputations for quality or inefficiency that, under an ACO regime, doctors will no longer be willing to affiliate with them. The ACO regime could effectively destroy some hospitals' economic viability. In these circumstances, local government officials could have to determine whether to let the hospital close or attempt to reconstitute in some way-for instance, as a less-than-full service facility providing emergency care or other services essential to the nearby community. In this scenario, local governments may need funds to subsidize the facility.

Doctors with privileges only at a closed hospital would have to find another ACO, and some may need to have admitting privileges at the base institution to join another ACO. Credentialing committees, in deciding whether to accept displaced doctors, would presumably consider two main factors: the optimum number of doctors needed to maintain satisfactory access to beneficiaries (assuming that CAHPS access scores are one of the performance bonus criteria), and the likelihood that the individual doctor would add to or subtract from the ACO's efficiency and quality. Therefore, the ACO proposal contemplates the possibility that in high utilization areas, not only will facilities close but also, some doctors will have to relocate to underserved areas or leave the practice of medicine.

Trickier issues still are raised by diverging interests of the doctors and the hospital to which they are attached. A localized SGR and shared savings regime mean the doctors' gains come at the hospital's expense. The ACO regime is based on the premise that hospitals in high-utilization areas will resign themselves to downsizing and cooperate with doctors by allowing their infrastructure (primarily, their committee structure and support units) to be harnessed for efficiency and quality improvement efforts. However, hospitals could try to block these efforts. For instance, hospitals will be busier with more interventionists in their ACO pool and will earn the most if doctors who perform profitable procedures continue to do so at a high volume. In contrast, doctors in the ACO can boost their conversion factor most quickly by identifying procedures that are performed at very high rates relative to the rest of the nation and curtailing them.

To illustrate, imagine an ACO formed around a hospital such as Elyria, Ohio's EMH Regional Medical Center, which recently gained notoriety 
for performing angioplasties at four times the national rate. According the New York Times, about 1,000 such procedures are performed on Medicare patients there each year. ${ }^{72}$ Using numbers reported in the article, it appears that if the rate were pared down to the national average, the number of procedures would be around 250 and some $\$ 600,000$ in savings would be made available for the ACO's doctors to share in the form of a higher conversion factor. Such a reduction, however, would cut the hospital's revenues by as much as $\$ 8$ million-a substantial portion of the hospital's profits. ACO doctors would presumably act through the hospital's committee structure to reduce capacity. The hospital could attempt to block such a maneuver, but ACO doctors would still be able to stop referring patients for angioplasties or affiliate themselves with a competing ACO.

A desirable consequence of such conflicts would be a new demand for clinical effectiveness data. Cardiologists whose practice would be threatened in these scenarios would have an incentive to fund research demonstrating the value of performing their procedure on a wider array of patients. If they were able to demonstrate that the procedure was reducing mortality in the population served by the ACO, they could argue that they were helping the ACO to earn a performance bonus.

Protracted conflicts could lead to litigation and perhaps even to interruptions in access to care. Also, it would be expected that some hospitals would close their doors. It might be necessary for an ACO regime to include local health care "czars" with the power to mediate and arbitrate disputes, or order "cooling-off periods," much as occurs in the labor sphere.

As has been noted by others, quality measurement efforts can lead to increased costs to Medicare. ${ }^{73}$ In one category of measurements are improved outcomes with quantifiable savings to Medicare, e.g., avoided hospitalizations. It is relatively easy to reward this quality dimension, by awarding shared Part A savings to the ACOs that achieve it. But a second category of quality indicators comprises processes recommended for the care of certain illnesses that will not, in the short run at least, lead to cost savings and that, because they are under-used, will certainly lead to higher costs. One example might be "Colonoscopic Surveillance After Colon Cancer." In a third category are improved outcomes that benefit the population served and thus have economic value to society but not a value that is reflected in lower Medicare costs. Examples here are mortality rates for medical conditions or surgical procedures

These latter categories create dilemmas because they either require additional Medicare expenditures for underused services, or merit increased

72. Reed Abelson, Heart Procedure Is Off the Charts in an Ohio City, N.Y. TIMES, Aug. 18, 2006, at A1, available at http:/www.nytimes.com/2006/0818/business/18stent.html.

73. See, e.g., Albert H. Guay, Understanding Pay for Performance, ADA NEws TODAY, Feb. 13, 2007. http://www.ada.org/prof/resources/pubs/adanews/printarticle.asp ?articleid $=2344$. 
pay to doctors to incent their achievement, or both. Since they cannot be paid for by self-generated savings they must be paid for either by transferring existing funds from low-performance regions or by committing new money.

Yet another question is whether a system of sub-national SGR pools would have any more viability than the current SGR regime, from which doctors have been able to engineer breakouts on an annual basis.

As an artificial legislative construct, the SGR has been vulnerable to what might be called a circumvention strategy by doctors-lobbying Congress to "replenish" the pool by reversing negative updates. Attempts to circumvent the SGR by lobbying should have been foreseen by policymakers. An earlier analog to the SGR, the Allowable Sale Quantity (ASQ) regime governing sustainability of national forests, had proven vulnerable to circumvention by logging interests, most notably in 1995 when the "salvage rider" was enacted. ${ }^{74}$ The politics of the salvage rider and the politics of the update reversals are strikingly similar: the affected interest group protests that restrictions are too onerous and a "crisis" threatens the public; in the case of the salvage rider, unemployment; in the case of the negative update, reduced access to care.

If the ASQ can be circumvented despite vociferous opposition from environmental groups, it is all the more unrealistic to expect that the SGR will not be circumvented given that the doctors' lobbying has faced no organized opposition. The biggest question raised by the shared accountability approach to the SGR is whether doctors would alter their practices to comply with the spirit of the new regime, or continue to try to "beat" the system by maintaining or increasing volume and then pleading for relief from the resulting "crisis."

There is no legal barrier preventing Congress from abrogating a statutory scheme that it created. There are practical barriers, however, that can prevent an interest group from succeeding in a circumvention strategy. The "crisis" must get on the congressional agenda, and members of Congress must be sympathetic. For an SGR regime to remain secure from circumvention, it should refrain from creating a compelling focusing event that can create a crisis atmosphere, and it must command respect and legitimacy that enable it to withstand frequent attacks. Currently, the SGR results in negative updates for every doctor in the country, allowing doctors to mount nationwide campaigns themed around the message of a nationwide access-tocare threat. This message gains a sympathetic hearing because few believe that 600,000 -plus U.S. doctors are capable of acting in concert to maintain steady utilization, and consequently appear blameless for their impending cut in pay.

74. Don Hopey, Vote Near on Rule Allowing More National Forest Logging, Pittsburgh Post-Gazette, Jul. 29, 1996, at B1. 
The splitting of the nationwide SGR pool into smaller pools would probably be a step toward eliminating both of these conditions. With smaller pools, doctors would no longer be affected uniformly by a negative update. Presumably, doctors in the "benchmark" localities identified by Dartmouth would receive positive updates simply by practicing as they have in the past, and would have no reason to quarrel with the system. Instead, negative updates would be limited to a subset of doctors in highintensity utilization regions, and complaints from this smaller number of doctors would carry less political weight.

This is not say that members of Congress from those regions would not be willing to step in and advocate for local doctors, especially if the cost of reversing a negative update could be spread nationwide. But if the localized SGR system gave doctors real tools to control their destinies, their pleas for relief would be less well-received. Giving doctors the opportunity to choose their EHMS pool or opt into a separate IPA pool would be important to creating a sense that doctors are not victims of but rather agents of the negative update's onset.

Congressional particularism is easiest when benefits are concentrated and costs are diffused. ${ }^{75}$ But with sub-national SGRs, efforts by a member of Congress or the HHS Secretary to give a positive update to physicians would have concentrated benefits and concentrated costs-increases in copayments for Medicare beneficiaries within the locality and possibly increased premiums as well, if Congress or the Secretary conditioned the positive update on its costs being recovered from within the service area affected.

\section{CONCLUSION}

A shared accountability regime holds out the promise of improving efficiency, quality, and patient-centeredness while preserving two additional values of critical importance to stakeholders - autonomy for doctors and choice for patients. Other models of cost-containment have been perceived to require sacrifices of one or more of these values.

The shared accountability approach also addresses critiques of the Medicare from two often disgruntled factions of the program's observers. An intriguing possibility is that accountable care organizations might bridge the divide between defenders of traditional Medicare and doctrinaire conservatives, who would prefer either a voucher/subsidy approach ("premium support") or consumer-directed approach ("medical savings account") that minimizes the federal role in providing health care. Because payments to physicians could vary greatly from the prices in Medicare's fee schedule

75. See R. Douglas ARnold, The Logic of CONGRessional ACtion (Yale University Press 1990). 
depending on the ACO's performance, and players within the ACO would be free to provide services, such as care coordination, that are not covered by Medicare's fee schedule, the ACO regime could effectively revoke Medicare's administered pricing system, making the schedule a reference point for payment instead of the last word. Such a development would be welcome to conservatives. John Goodman appeared to endorse the ACO concept in a Wall Street Journal op-ed, writing

Under the current system, Medicare and Medicaid stifle entrepreneurial activity and financially punish efforts to lower cost or improve quality. Why can't these agencies reward improvements instead? Suppose an entrepreneur offered to replicate the Mayo Clinic in other parts of the country-potentially saving Medicare $25 \%$ of costs and improving quality of care along the way. Medicare should be willing to pay, say, $12.5 \%$ more than its standard rates in order to achieve twice that amount in total lower costs. ${ }^{76}$

Accountable care organizations could also address the desire of health policy experts for what James Robinson has called "payment methods that blend collective capitation with individual fee-for-service." noted that "the formation of virtual specialty departments that can be assigned a predetermined budget" ${ }^{\prime \prime 8}$ would lead to

individual specialists in these virtual departments... [thinking] of each other as collaborators, not simply as competitors, and will [provoke them to]... begin to adopt specialty-specific clinical protocols... Ideally, this improves the cost-effectiveness of the services provided, since peer monitoring and disciplining of inappropriate behavior is easier within specialty lines than across them. It provides a spur to the creation of specialty protocols, the screening and selection of departmental members, cross-specialty discussions of what constitutes an appropriate referral, and, more generally, the first whispers of collective professionalism in what traditionally has been the

76. John C. Goodman, "Perverse Incentives in Health Care," Wall Street Journal, April 5, 2007.

77. Robinson, supra note 52, at 161.

78. Id. 
most autarkic of occupations. ${ }^{79}$

The accountable care organization approach offers the possibility of the blended payment system that Robinson and other health policy analysts have advocated.

While no one can say whether a full-blown ACO system would accomplish all the goals discussed in this paper, the availability of informal means of testing the concept, as through the Medigap or "competitive dynamic" options outlined above, means that there are opportunities to experiment with shared accountability on a limited or voluntary scale.

79. Id. 
